\title{
Emotional Intelligence and Social Support as Predictors of Life Satisfaction among Hospital workers
}

\author{
Kolade Janet Tolulope ${ }^{1}$, Dennis Uba Donald ${ }^{2}$ \\ Department of Pure and Applied Psychology, Adekunle Ajasin University Akungba-Akoko, Ondo State, \\ Nigeria \\ Department of Pure and Applied Psychology, Adekunle Ajasin University Akungba-Akoko, Ondo State, \\ Nigeria
}

\begin{abstract}
The study investigated emotional intelligence and social support as predicators of life satisfaction among hospital workers in Lagos, State, Nigeria. The purpose of his study is to investigate the relationship between emotional intelligence, and social support as predictors of life satisfaction among hospital workers. Life satisfaction was explained using Veenhoven's (1984) Quality of Life (QOL) Model; Emotional Intelligence was explained with the Emotional Intelligence Model by Salovey. Two direct research hypotheses were formulated. A cross-sectional survey design was adopted in the study. Participants (hospital workers) across various grades of each of the selected hospital were accidentally sampled. The dependent variable is life satisfaction. The predictor variables are emotional intelligence, and social support. This study was conducted using, expost facto factorial design since it attempted to explain effect based on precursory condition, to determine the influence of a variable on another variable. Doctors and nurses in Lagos state metropolis, Nigeria constitutes the population of this study. The result of the study indicated that emotional intelligence significantly predicted life satisfaction $(\beta=0.473, p<$ 0.01). The result confirmed hypothesis 1 , therefore, the hypothesis was accepted. The prediction of life satisfaction by social support was significant $(\beta=0.872, p<0.01)$. The finding confirm hypothesis 2 and it was accepted. The result also indicated that emotional intelligence, and social support jointly contributed a significant variance of $84.6 \%$ to the total variance noted in life satisfaction among health workers $[\mathrm{F}(2,183)=242.342$, $\mathrm{p}<$ 0.01]. Based on the findings of this study, the researcher recommends as that healthcare practice needs more evidence that is proved by scientific research results in other to establish a cause and effect relationship among study variables.
\end{abstract}

Keywords: Life Satisfaction, Emotional Intelligence, Self Esteem, Social support, Gender, Marital status, Heath workers

\section{INTRODUCTION}

Health workers and various governments world over are constantly at each others throat for issues surrounding welfare or better life satisfaction. This trend is synonymous to Nigeria as health workers strike has dominated the news in recent times. The risk accrued from healthcare service is often life threatening (Alao, 2008; Strine, Chapman, Balluz, \& Mokdad, 2008). Some literatures have demonstrated the importance of factors like remuneration, organisational culture, organisational support and leadership style (Elusiyan, 1994; Oladipo, Olapegba \& Adenaike, 2010; Onyishi, Okongwu, \& Ugwu, 2012; Iheonunekwu, Anyatonwu, \& Eze, 2012). With the advent of strikes and boycotts occasioned by the Nigerian Medical Service, it is obvious that healthcare employees are aggrieved and there have been reported cases where medical practitioners in Nigeria have clamoured for an improvement in welfare and safety with issues like health insurance and salary packages that cover for the hazards of medical practice (Ojoawo, Igudia, Mbada, Onigbinde, \& Adedoyin, 2013; Iheonunekwu, Anyatonwu, \& Eze, 2012).

The study investigated emotional intelligence and social support as predicators of life satisfaction among hospital workers in twenty public and private owned hospitals situated in Amuwo-Odofin, Kosofe, Eti-Osa, Surulere, and Ifako-Ijaiye Local Government areas in Lagos, State, Nigeria Creating opportunities and situations that will generate satisfaction with life among Nigerians is worthwhile and desirable (Adebayo \& Arogundade, 2011). Viewed from different perspectives, satisfaction with life is a desirable psychological condition for every human being, especially, considering the benefits accruable from such condition, and the opportunities the psychologically

\footnotetext{
${ }^{1}$ Corresponding Author: koladejanet@yahoo.com
} 
healthy condition could offer individuals in the different spheres of one's life endeavours (Adebayo \& Arogundade, 2011). Evidences abound, that people who are satisfied with their lives tend to be more creative and more pleasant to be with (Denovan \& Helpen, 2000; Malinauskas, 2010; Ojoawo, Igudia, Mbada, Onigbinde, \& Adedoyin, 2013), are less likely to get divorced, perform better at work, and even live slightly longer (Krause, 2004; Adebayo et al., 2011).

It appears that all individual activities are directed towards making life more worthwhile and meaningful as well as the desire for happiness has been understood as a fundamental and universal human drive (Wright, \& Cropanazano, 2000; Ho, Cheung, \& Cheung, 2008). In recent times, social scientists and other researchers in related fields have focused attention on satisfaction with life across different categories of people, including the young and the old (Wong, Oie, Ang, Lee, Ng, \& Leng, 2007; Joshanloo \& Afshari, 2011; Seitz, et al., 2011).

Life satisfaction has been acknowledged as one of the three mechanisms of subjective well-being (Diener, 1984). Satisfaction in life is defined as one's overall assessment derivable from the comparison between one's aspiration and one's achievement (Ho, et al., 2008). Life satisfaction connotes the outcome of self assessment, depending on one's expectation. It is determined by one's perception of how things are and how they should be. The smaller the gap, the more satisfied the person becomes (Strine, Chapman, Balluz \& Mokdad, 2008; Seitz, et al., 2011).

Healthcare work is typified by stress (Finn, 2000). Healthcare workers officers report increased absenteeism (Brodsky, 1982) and low life satisfaction (Adebakin, 1990). Since job satisfaction has been associated with general life satisfaction (Robbins \& Kliewer, 2000), it is therefore necessary to investigate life satisfaction of employees, especially group of workers such as health workers that have been found to have low satisfaction in their jobs. The advantages of satisfaction with life in work setting are enormous, it reflects on workers physical and psychological disposition and overall wellbeing. Life satisfaction has been linked to longevity and performance, reduced absenteeism, and increase in work motivation (Rode, 2004). This is evident as employees puts in their best when they are satisfied. Happy workers are productive workers, not necessarily because of job satisfaction (Krause, 2004), but because they are satisfied with life in general (Wright \& Cropanzano, 2000). It is assumed then that hospital officers will be more productive when they are satisfied with their life. Thus, it is important to explore correlates of life satisfaction among workers in the health care service.

\subsection{Emotional Intelligence}

The concept of emotional intelligence (EI) was first proposed by Mayer \& Salovey (1990) which was then popularized by Goleman: Why it can matter more than IQ". Since then, this area has got much attention in the field of healthcare delivery systems, leadership, human resource management and organizational behavior. EI came up from the work of social intelligence by Thorndike (1920) concept of intrapersonal and interpersonal intelligence.

Dimensions of emotional intelligence comprises four abilities, Appraisal and Expression of Emotion (own and others), Use of Emotions and Emotional Management (own and others) (Wong \& Law, 2002). Appraisal and expression of emotions is the first factor of EI and is the ability to properly determine and express one's own emotions as well as to be sympathetic, appraise and express emotions of others (Goleman, 2002). Every individual's ability varies in precisely identifying, appraising and expressing his own emotions as well as the emotions experienced by others. Some people are attentive of their feelings they experience and can express their emotions whereas, some people cannot express their feelings and emotions or they are unaware of their emotions (Zhou \& George, 2003).

\subsection{Purpose of Study}

The purpose of his study is to investigate the relationship between emotional intelligence, and social support as predictors of life satisfaction among hospital workers. However, the precise purpose of this study is to: Examine whether emotional intelligence and social support as predictors of life satisfaction among hospital workers in Lagos Nigeria.

\subsection{Literature Review}

Life satisfaction was explained using Veenhoven's (1984) Quality of Life (QOL) Model; Emotional Intelligence was explained with the Emotional Intelligence Model by Salovey.

Quality Of Life (QOL) Model

Veenhoven's (1993) quality of life models the term 'quality of life' signifies two meanings: 1) the presence of conditions considered necessary for a good life, and 2) the practice of good living (Veenhoven, 1984; 1990; 1991; 
1993; 1994). When used at the societal level, only the former meaning applies. The first survey studies which used measures of life-satisfaction were performed in the USA in the 1960's. The emphasis at that time was on mental health. The results from some of this research appeared in books by Gurin et al (1960) and Bradburn (1969) cited in, Veenhoven (1989). In the 1970's, life-satisfaction was a central theme in several American social indicator studies (1992). Veenhoven (1995) theorized that present life changes are rooted in past events and change-structures; in societal history as well as individual development.

Conclusively, the subject of life-satisfaction has for long been the subject of philosophical speculation. Lack of valid measures of life-satisfaction has meant that the various propositions could not be empirically tested. Hence, knowledge on life-satisfaction has remained speculative and uncertain (Seligman, 2002). Survey research methods introduced by the social sciences have brought about a break-through. Fairly dependable measures of lifesatisfaction have been developed, and by means of these measures a significant body of knowledge has evolved. Hence, researchers are now in a position to empirically weigh the evidence in support of the various theoretical positions (Denovan \& Halpen, 2000; Seligman, 2002).

\subsection{Emotional Intelligence Model}

The concept of emotional intelligence (EI) was first proposed by Mayer \& Salovey (1990) which was then popularized by Goleman: Why it can matter more than IQ". Since then, this area has got much attention in the field of leadership, human resource management and organizational behavior (Seligman \& Csiksentunihalyi, 2002). EI came up from the work of social intelligence by Thorndike (1920) and Gardner's (1983) concept of intrapersonal and interpersonal intelligence. Thorndike classified Intelligence into three types: Abstract Intelligence which is related to verbal concepts, Concrete Intelligence which is related to shapes and matter and thirdly Social Intelligence now termed as Emotional Intelligence. It shows that it is not a new concept. The researchers have defined EI as a distinct psychological skill that can be consistently measured (Stough, Saklofske, \& Parker, 2009). Salovey \& Mayer (1990) defined emotional intelligence as the subset of social intelligence that involves the ability to monitor one's own and others' feelings and emotions, to discriminate among them and to use this information to guide one's thinking and actions. Their model includes features of intelligence, adjustability and encouragement.

\subsection{Dimensions of Emotional Intelligence}

Emotional intelligence comprises four abilities, Appraisal and Expression of Emotion (own and others), Use of Emotions and Emotional Management (own and others) (Wong \& Law, 2002). The first factor of EI is the ability to properly determine and express one's own emotions as well as to be sympathetic, appraise and express emotions of others. Every individual's ability varies in precisely identifying, appraising and expressing his own emotions as well as the emotions experienced by others. Some people are attentive of their feelings they experience and can express their emotions whereas, some people cannot express their feelings and emotions or they are unaware of their emotions (Zhou \&George, 2003). Previous studies were reviewed in order to provide a representation of the interrelatedness of all variables and the chasm or hollow generated by these literatures.

\subsection{Emotional Intelligence and Life Satisfaction}

Relationship of emotional intelligence with life satisfaction has been demonstrated in several literatures (Goleman, 2005; Qquoidbach \& Hansenne, 2000; Stough, Saklofske \& Parker, 2009). As emotional intelligence is critical to life satisfaction, a person who knows how to stay motivated under stress, motivate others, manage complex interpersonal relationships, his/her others and build teams who are recognized specialists on a product or service are likely to get will get better results (Goleman, 2005; Schimmack, Oishi, Furr \& Funder, 2004). Emotional intelligence is a multi-dimensional concept that links emotion and cognition to improve human interactions (Goleman, 2005). It has been linked to improved workplace behaviour and specifically health team behaviour and health team performance (Qquoidbach \& Hansenne, 2000). In recent research, by Stough, Saklofske \& Parker, (2009) it was found that life satisfaction is positively and significantly influenced if team is able to recognize emotions of teammates.

Though there are many claims regarding the positive impact of emotional intelligence on quality of life, but the studies examining the relationship between emotional intelligence and individual quality of life perception show that the perceived potential benefits of using emotional intelligence in the workplace may be absent (Sy, Tram \& O'Hara, 2006; Seitz, et al., 2011). Qquoidbach \& Hansenne (2000) and Jordan \& Troth (2004) have found a correlation between emotional intelligence and life satisfaction on a purely cognitive task at group level, although this relationship did not appear at individual level. 
Further, studies in Nigeria by Umeh, (2004); Agbo, Nzeadibe, \& Ajaero, (2012) found that employees having high emotional intelligence are more skilled to regulate their own as well as manage others' emotions to promote positive interactions which would lead to higher performance. This is also substantiated by Sy, Tram \& O'Hara (2006) who revealed that individuals high on emotional intelligence tend to foster relationship among colleagues in work place settings. Similarly, Adewuya, Afolabi, Ola, Ogundele, Ajibare, Oladipo \& Fakande, (2010) revealed that healthcare managers having high emotional intelligence exhibit optimistic work attitudes and unselfish behaviors which resultantly lead to employees' higher life satisfaction and performance at job. In similar vain, Ayoko \& Callan, (2009); Jordan, Ashkanasy, Hartel \& Hooper, (2002); Iheonunekwu, Anyatonwu \& Eze, (2012), reported that individuals who show high emotional intelligence often possess a positive outlook of life.

\subsection{Social Support and Life Satisfaction}

Social support has been considered a meta-construct with multiple dimensions, which makes measurement of the concept intricate (William, Barclay \& Schmeid, 2004). Critical reviews in literature on social support have pointed to the use of heterogeneous methods and metrics as a hindrance in understanding the true effects of social support on varying outcomes (Decker, 2006; Uchino, 2006; DiMatteo, 2004; Holt-Lunstad, Smith, \& Bradley Layton, 2010).

For example, Strine, Chapman, Balluz \& Mokdad, (2008) analyzed data from a state-based surveillance system that collected data on social support, health-related quality of life, and health behaviors and discovered that those who reported lower levels of social support had increased obesity, physical inactivity, alcohol consumption, and a higher prevalence of smoking. Although the exact means by which social support contributes to health and the factors that influence this relationship are not yet entirely understood (Seeman, 2006), these findings indicate that social support can affect and encourage engagement in positive health behaviors or life satisfaction (William, et al., 2004).

Indeed, support from friends and family can promote workers performance (Sun, Zhang, Fu, 2007), as it buffers the stress associated with the work related illness (Zimet, Powell, Farley, Werkman, \& Berkoff, 1990), encourages optimism (Zhou\& George, 2003), reduces depression (Au, Lau, Koo, Cheung, Pan, \& Wong, 2009), and improves healthful behaviors (Seeman, 2006). In a recent meta-analysis, DiMatteo (2004) identified 122 studies published between 1948 and 2001 that correlated social support with life satisfaction across multiple medical staffs. The study found that medical staffs that had sufficient social support were over two times more likely to experience life satisfaction; social support also had a greater effect on among senior medical health workers who had access to improved allowances.

However, not all studies on social support demonstrate benefits (Adewuya, Afolabi, Ola, Ogundele, Ajibare, Oladipo, \& Fakande, 2010). Wills and Vaughan (1989) cited in, (Lyyra \& Heikkinen, 2006) found that some social relationships might actually encourage partaking in unhealthy behaviors, such as drinking alcohol, smoking, and drug use among adolescents. Additionally, findings from DiMatteo (2000), suggest that social support can enhance stress. Nigerian studies (Oladipo, Olapegba \& Adenaike, 2010) have revealed that the most effective form of support is that which is "invisible," in that the recipients of support are unaware of the assistance they've received. Oladipo, Olapegba \& Adenaike, (2010) examined satisfaction with life among 1429 undergraduates from Southwestern Nigeria. Ex post facto survey design was adopted and convenient sampling method was used. Four hundred and seventy five (475, i.e. $33.2 \%)$ males and $953(66.8 \%)$ females, ages ranging between 16 to 27 years $(\mathrm{M}=28.47, \mathrm{SD}=$ 8.76). Validated scale was used for data collection and the two hypotheses stated were confirmed after testing with appropriate statistics. A total of 837 undergraduates (58.57\%) had scores less than the midpoint of 20; their mean was 14.03 ( $\mathrm{SD}=2.42) .88(6.2 \%)$ scored exactly 20 , while $504(35.33 \%)$ scores were higher than 20. Oladipo, Olapegba \& Adenaike, (2010) concluded that undergraduates low satisfaction with life and there is no significant difference between males and females regarding satisfaction with life. In light of these it would be imperative to ask some relevant question:

1. Would emotional intelligence predict life satisfaction of hospital workers in Nigeria?

2. Would social support predict life satisfaction of hospital workers in Nigeria?

Research Hypotheses:

1. Emotional intelligence will independently significantly predict life satisfaction.

2. Social Support will independently significantly predict life satisfaction 


\section{METHOD}

\subsection{Research Setting}

A cross-sectional survey design was adopted in the study. Participants (hospital workers) across various grades of each of the selected hospital were accidentally sampled. The dependent variable is life satisfaction. The predictor variables are emotional intelligence, and social support. This study was conducted using, expost facto factorial design since it attempted to explain effect based on precursory condition, to determine the influence of a variable on another variable. Doctors and nurses in Lagos state metropolis, Nigeria constitute the population of this study because a considerable number of health workers would be accessed in Lagos state which are strategically located in the hub of the most populous nation in Africa. The pluralistic, commercial, and strategic nature of Lagos state informed the locale of research used in the study. A total of 197 doctors and nurses across eight (8) government and twelve (12) private owned hospitals in Amuwo-Odofin, Kosofe, Eti-Osa, Surulere, and Ifako-Ijaiye Local Government areas in Lagos, Nigeria metropolis were used. The public hospitals selected were; Ebute-Metta Health Centre, Harvey Road Health Centre, Ifako-Ijaiye General Hospital, Agbowa General Hospital, Ketu-Ejinrin General Hospital, Onikan Health Centre, Surulere General Hospital and Ibeju-Lekki General Hospital. The private owned hospitals were: Shepherd Medical Centre, Reddington Hospital, St. Francis Medical Centre, Paelon Memorial Clinic, Lagoon Clinic, Diagnostic and Therapeutic Endoscopy Centre (D\&TEC), Emel Hospital, Faith City Clinic, St. Michael's Hospital, First Consultant Hospital, Best Care Clinics and St. Georges Memorial Hospital.

The participants comprised of 91 (46\%) males and 106 (54\%) females. Marital status revealed single 73 (37\%) married 124 (62\%) and divorced 0 (0\%), also, Christians $112(56 \%)$, Islam $80(40 \%)$, Others 5 (2\%). Emotional intelligence had a mean score of 115.89 for the 33 -item, 5 point scale. Scores from the mean implies high level of emotional intelligence. Social support had a norm of 50 and scores below the mean implies low level of social support, while scores from the mean and above implies high social support. Life satisfaction had a mean of 51.8. This implies that scores from the mean are satisfactory while scores below the mean are not satisfied with their life.

\subsection{Instruments}

Relevant data were gathered through the use of validated questionnaire which comprises of four sections (A-D).

Section A: This section measured demographic variables which included: Age, Gender, and Religious affiliation.

Section B: Emotional Intelligence was measured using a 30 item self report Trait Meta-Mood Scale (TMMS) developed by Salovey, Mayer, Goleman, Turvey and Palfai (1995). TMMS measures the core areas of emotional intelligence: emotional attention (13 items), emotional clarity (11 items), and mood repair (6 items). Examples of items are: "Feelings give direction to life" (emotional attention), "when I become upset I remind myself of all the pleasures in life" (mood repair). The scale is predicted on a 5 point scale $(1=$ Strongly Disagree; 5 = Strongly Agree). All the items are directly scored except for items 5, 28, and 33 which are reversely scored. Fitness and Curtis (2005) cited in, Oladipo, Olapegba \& Adenaike, (2010) obtained 0.78, 0.85, and 0.78 Cronbach's alpha coefficients for emotional intelligence, emotional clarity, and mood repair sub scales, respectively. Using Nigerian sample, Ogungbamila (2011) obtained 0.70 and 0.78 Cronbach's alphas respectively for the overall scale. Scores above the mean reflect high emotional intelligence while scores below the mean indicate low emotional intelligence

Section C: The Multidimensional Scale of Perceived Social Support (MSPSS)

The MSPSS is a self report questionnaire developed to measure perceived social support. The MSPSS was developed by Zimet, Dahlem, Zimet \& Farley, (1988). The scale is a 12- item questionnaire, and a 7 point Likert type scale. The scale is scored in continues form with the responses ranging from very strongly disagree $=1$, to very strongly agree $=7$. Each item was scored 1-7. Total sum of all 12 items, possible range is 7-84. Total $=69-84$ indicates high acuity, 49-68 moderate acuity, and 12-48 signify low acuity. Samples of items include: "I have peace of mind in my family", "I have a good social relationship with my colleagues and other people around me", "I am satisfied with my marital status", "I am satisfied with my marriage", "I am satisfied with my spouse". Diener, Diener \& Diener, (1995) revealed a Cronbach's alpha of .79 and reported of a correlation between life satisfaction and subjective wellbeing.

In Nigeria, Ojoawo, Igudia, Mbada, Onigbinde, \& Adedoyin, (2013) reported that, a Cronbach's alpha of .82 and the response rate obtained from their study was $80 \%$. Further, Ojoawo, et al., (2013) reported that the mean total life satisfaction of the respondents was $151-180$. There was a significant difference in total life satisfaction scores at $p$ $<0.001$ between the single and married respondents, first degree and postgraduates and between entry physiotherapist and senior physiotherapist. There was a significant association between level of life satisfaction and 
level of education, at $p<.05$. There also was a significant association, $p<001$, between the level of life satisfaction and age, social support and cadre.

\section{Section C: The Life Satisfaction Scale Questionnaire (LSSQ)}

The Life Satisfaction Scale Questionnaire (LSSQ) was used as was adapted from Satisfaction with Life Scale (SWLS) (Diener, Diener \& Diener, 1995; Alao, 2008). Alao, (2008) asserted that validity was satisfactory ( $\mathrm{r}=0.75$, $p=0.001)$. The LSSQ is a two-section questionnaire comprised of a total of 29 questions. Section A comprises 6 items designed to assess demographic information of the respondents, i.e., age, sex, highest educational qualification, marital status, cadre and religion. Section B consists of 29 items designed to measure the life satisfaction of the respondents. The questions on perceived level of satisfaction in different domains are on a 7-point scale ranging from 7 (strongly agree) to 1 (strongly disagree) for each question. One question (q) (q.1) asked about satisfaction in family life. Two questions (q. 2,3) sought satisfaction in terms of the realization of dreams and aspirations, two questions (q. 4,5) asked for satisfaction with social life, five questions (q. 6,7,8,9,10) asked about the conditions of life, 3 questions (q. 11,12,13) rated their satisfaction with their health, five questions (q. 14,15,16,17,18) assessed job satisfaction, six questions (q. 19,20,21,22,23,24) asked about finances, and five questions (q. 25,26,27,28 and 29) assessed satisfaction in marital life. The questionnaire took between 5-10 minutes to answer and was collected immediately from the respondents. Respondents' scores range from 29-203, signifying 'extremely dissatisfied' to 'extremely satisfied'. A score range of 203-181 was classified as 'extremely satisfied', 151-180 as 'satisfied', 121-150 as 'slightly satisfied', 120 as 'neutral', 90-119 as 'slightly dissatisfied', 60-89 as 'dissatisfied', and 29-59 as 'extremely dissatisfied'.

\section{Procedure}

In a bid to get the health workers that participated, authorization and approval was sought in form of informed consent before they were selected for assessment in the study. The respondents were adequately informed about the nature of the study and its benefits. The purpose of the study was explained to the participants as they were also given assurance of confidentiality and anonymity of their identities and responses. The purpose of the study was explained to the participants as they were also given assurance of confidentiality and anonymity of their identities and responses.

Using accidental sampling the researcher administered two hundred and three questionnaires to doctors and nurses across various departments who consented in such a way that averages of 9 copies of questionnaire were administered per hospital. Accidental sampling technique and not randomization was used since most doctors and nurses are always busy and the roaster table situations in most hospitals did not allow for a more thorough sampling technique. As a result, the only way to get sustainable responses is by using this non-probabilistic method. Although, two hundred and three (203) copies of questionnaire were administered but only two hundred (197) copies of questionnaire were found usable for the analysis. This yielded a response rate of $97.0 \%$.

\section{DATA ANALYSIS}

In order to determine the extent and direction of associations among the study variables, Pearson Product Moment Correlation (PPMC) analysis was conducted. Multiple regression analysis was then used to test hypothesis 1 and 2. Some of the socio-demographic variables were codified. For example, gender was coded male 0, female 1. All analyses were conducted using SPSS 17.0 Wizard.

Results: Test of Relationship among the Study Variables

The first analysis involved inter-correlations of all the variables of the study. The result presented in table 1.0

Table1. Correlation Matrix Showing the Mean, SD and Inter-variable Relationships among Variables of the Study

\begin{tabular}{|l|l|l|l|l|l|l|l|l|l|}
\hline Variables & Mean & SD & 1 & 2 & 3 & 4 & 5 & 6 & \\
\hline 1. Gender & - & - & 1 & & & & & & \\
\hline 2. Age & - & - & $.121^{*}$ & 1 & & & & & \\
\hline 3. Religion & - & - & .057 & .121 & 1 & & & & \\
\hline 4. Emotional Intelligence & 71.60 & 25.07 & -.077 & .037 & -.022 & 1 & & & \\
\hline 5. Social Support & 53.07 & 17.34 & .042 & .070 & .086 & .012 & 1 & & \\
\hline 6. Life Satisfaction & 62.66 & 10.59 & .065 & .123 & .119 & $.615^{* *}$ & $.884^{* *}$ & 1 & \\
\hline
\end{tabular}

$* * p<0.01, * p<0.05, N=197$ 
The findings revealed that there was a significant association between emotional intelligence and life satisfaction [ $\mathrm{r}$ $(198)=.615, \mathrm{p}<0.01]$, such that when hospital workers emotional intelligence increases, their life satisfaction tend to increase. Social support indicated a positive significant relationship with life satisfaction $[\mathrm{r}(198)=0.884$, $\mathrm{p}<$ 0.01] such that social support increases with increase changes in life satisfaction. The demographic variables under the study (gender, marital status and religion) had no significant connection with life satisfaction of hospital workers.

The test for the formulated hypotheses was carried out using multiple regression analysis and the result was presented below in Table 1.1

Table1.1. Summary of Multiple Regression Analysis Showing the Prediction on Life satisfaction

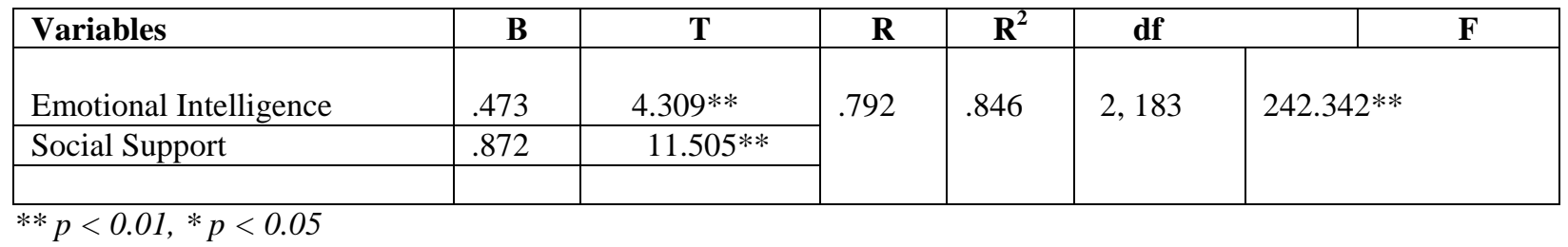

The result above indicated that emotional intelligence significantly predicted life satisfaction $(\beta=0.473, p<0.01)$. This was such that increase in emotional intelligence will result to an increase in the life satisfaction among hospital workers. The result confirmed hypothesis 1 , therefore, the hypothesis was accepted. The prediction of life satisfaction by social support was significant $(\beta=0.872, \mathrm{p}<0.01)$. This implies that an increase level of social support received by hospital workers will determine and lead to an increase in their life satisfaction. The finding confirm hypothesis 2 and it was accepted. The result in Table 1.1 also indicated that emotional intelligence, and social support jointly contributed a significant variance of $84.6 \%$ to the total variance noted in life satisfaction among health workers $[\mathrm{F}(2,183)=242.342, \mathrm{p}<0.01]$.

\section{DISCUSSION}

The study investigated emotional intelligence and social support as predicators of life satisfaction among hospital workers in twenty public and private owned hospitals situated in Amuwo-Odofin, Kosofe, Eti-Osa, Surulere, and Ifako-Ijaiye Local Government areas in Lagos, State, Nigeria. The findings demonstrated that there was considerable relationship between emotional intelligence and life satisfaction meaning that when workers in the hospital emotional intelligence increases, life contentment in relation to life satisfaction tend to increase. The result uphold with the result presented by Ojoawo, et al., (2013) who cited that emotionally intelligent individuals are often able to adapt at putting themselves in positive affective states to avoid dysfunctional emotions and use them in adaptive ways to alleviate the feeling of frustration than health workers with low emotional intelligence. Goleman, (2005) also affirm emotional intelligent individuals may be optimistic; a trait that may enable them to focus on the resolution, rather than the reasoning (i.e. who made the error). All these added up would provide leverages to develop life satisfaction than their other counterparts. This finding gained support from the works of previous researchers who reported that the higher the level of emotional intelligence of an individual the higher the life satisfaction (Doğan, Deniz, Odabaş, Özyeşil \& Özgirgin, 2012).

The prediction of life satisfaction by social support was significant $(\beta=0.661, p<0.01)$. This implies that an increase level of social support received by hospital workers will determine and lead to an increase in their life satisfaction. Social support has been implicated in some studies to be a reliable basis of life satisfaction (Anne, 2004). Further, Onyishi, Okongwu \& Ugwu, (2012) findings support the findings of the present study who revealed that social support is positively related to life satisfaction. Support from friends significant others and family supports were significant predictors of life satisfaction among the participants. The implications to research and clinical practice are that increase in social support has been associated as a co-morbid factor which leads to increase in overall subjective life satisfaction and depression (Malinauskas, 2010), while lower social support leads to decrease in life satisfaction and health related issues like depression (Newson \& Schulz, 1996; Fuentesl, \& Rajasl, 2004). Studies have shown that friends and family support significantly predicted life satisfaction (Au, Lau, Koo, Cheung, Pan \& Wong, 2009). Also, Kraus (2004) noted that most people turn to social resources in an effort to contain stressful events in life. In this case, support network is an indication of social integration and the more one is integrated, the more one can cope with the effects of stressful life event. Dollete, Steese, Phillips \& Matthews, (2004) who found that social support could act as a protective factor that could decrease psychological problems among health workers such as stress. A study by Wentzel (1998) cited in Calvete et al., (2006) found that social 
support provides motivational influence on workers performance because social support includes social resources that individuals perceive to be available or that are actually offered to them which could help protect against psychological problems.

\section{CONCLUSION}

Based on the findings, the study has empirically demonstrated that health workers who perceived increase sense of emotional intelligence, and social support, showed higher tendency to demonstrate life satisfaction than their opposite number. Additionally, the results revealed that health workers who scored high on emotional intelligence and social support demonstrate high affinity to be content with life. The result of this study also showed that all the independent variables (emotional intelligence and social support) jointly predicted life satisfaction.

\subsection{Implications of the Findings}

Findings of the study have direct practical implications for management and owners of managed care institutions. The findings implicate the need for hospital and healthcare management to design and develop intervention programmes that can help increase effective life satisfaction and personnel wellbeing and development within the managed care sector.

\subsection{Recommendations}

Based on the findings of this study, the researcher recommends as that healthcare practice needs more evidence that is proved by scientific research results. Future research should integrate research evidence into emotional intelligence, social systems and other psycho-socio variables that point to the effects of the difficulties suffered by the hospital workers. It is therefore recommended that psychologist especially clinical psychologists should intensify more on comparative case studies to ascertain factors responsible for life satisfaction over along period of time.

\section{REFERENCE}

[1] Adebayo, S.O; \& Arogundade, B.O. (2011). Determinants of Significant Single Best Predictor of Life Satisfaction among Nigerian Adults. Interdisciplinary Review of Economics and Management.

[2] Adewuya, A. O., Afolabi, M. O., Ola, B. A., Ogundele, O. A., Ajibare, A. O., Oladipo, B. F., \& Fakande, I. (2010).The Effect of Psychological Distress on Medication Adherence in Persons with HIV Infection in Nigeria. Psychosomatics, 51(1), 68-73.

[3] Alao, O. (2008). The Relationship between Teacher's Effectiveness and Life Satisfaction. PhD Obafemi Awolowo University.

[4] Anne, C. (2004). Emotional Intelligence in Nursing Work. Journal of advanced Nursing. 47(1),101-108.

[5] Au, A., Lau, K., Koo, S., Cheung, G., Pan, P. C., \& Wong, M. K. (2009). The Effect of Social Support on Depressive Symptom and Life Satisfaction in Dementia Caregivers in Hong Kong. Hong Kong Journal of Psychiatry, 19: 57-64

[6] Ayoko, O. B., \& Callan, V., J. (2009). Teams' Reactions to Conflict and Teams' Task and Social Outcomes: The Moderating Role of Transformational and Emotional Leadership. Retrieved April 05, 2010 from www.elsevier.com/locate/emj

[7] Brodsky, C. M. (1982). Work Stress in Correctional Institutions. Journal of Prison and Jail Health, 2, 74-102.

[8] Calvete, H. \& Connor-Smith, J.K. (2006). Perceived Social Support, Coping, and Symptoms of Distress in American and Spanish students. Anxiety, Stress, and Coping, 19(1), $47-65$.

[9] Costa, P. T. \& McCrae, R. R. (1992) Revised NEO Personality Inventory (NEO-PI-R) and NEO five-factor (NEO-FFI). Inventory Professional Manual, Odessa, FL:PAR.

[10] Decker, C.L. (2006). Social Support and Adolescent Cancer Survivors: A Review of the Literature. Psycho-Oncology, 16, $1-11$.

[11] Dennis, U.D. (2014). The Curious Case of Medical Negligence in Nigeria. International Journal of Indian Psychology. Volume 2, Issue 1, No. 3. November, 2014 http://ijip.in/index.php/current-issue.html www.ijip.in

[12] Denovan, N. \& Halpen, D. (2000) Life Satisfaction: The State of Knowledge and Implications for Government. Accessed through mail at nicholas,denovan@ cabinetoffice.x.gsigov.uk.

[13] Diener, E. (1984). Subjective Well-Being. Psychological Bulletin, 95: 542-575.

[14] Diener, E. \& Biswas-Diener, R. (2002) Will Money Increase Subjective Well-Being? Social Indicators Research, 57:119169.

[15] Diener, E., Diener, M., and Diener, C. (1995). Factors Predicting the Subjective Well-Being of nations. Journal of Personality and Social Psychology, 69, pp. 851-864.1995)

[16] Diener, E. \& Lucas, R.E.(1999) Personality and Subjective Well-being. In D. Kahneman, E. Diener, and D. Schwarz (eds.) Well-being: The Foundations of Hedonic Psychology. (PP. 23-229). New York: Russell Sage Foundation. 
[17] DiMatteo, M.R. (2004). Social Support and Patient Adherence to Medical Treatment: A Meta-Analysis. Health Psychology 23(2), 207- 218.

[18] Doğan, A., Deniz, M. E., Odabaş, H., Özyeşil, Z. \& Özgirgin, N. (2012). Job and Life Satisfaction of the Medical Staff in Rehabilitation Centers. Turkish Journal of Physical Medicine and Rehabilitation, 58, pp. 16-21.

[19] Elusiyan, B. A. (1994) Relationship between Family Bond, Parental Education, Socio-Economic Status, and the Development of Delinquency. Unpublished M.Sc. Thesis. Department of Psychology, University of Lagos

[20] Finn, P. (2000). Addressing Correctional Officer Stress: Programs and Strategies. Washington, DC: National Institute of Justice.

[21] Goleman, D. (1998). Emotional Intelligence that Lead to Success. EI 2, 9-42.

[22] Goleman, D. (2005). Emotional Intelligence. (10th Ed). New York: Bantam Books. New York. London: Norton and Company.

[23] Ho, M. Y., Cheung, F. M., \& Cheung, S. F. (2008). Personality and Life Events as Predictors of Adolescents Life Satisfaction: Do Life Events Mediate the Link between Personality and Life Satisfaction? Social Indicators Research, 8: 475-471.

[24] Holt-Lunstad, J., Smith, T.B., \& Bradley-Layton, J. (2010). Social Relationships and Mortality Risk: A Meta-Analytic Review. P-LoS Medicine, 7(7), 1-19.

[25] Iheonunekwu, S., Anyatonwu, N., \& Eze, O. R. (2012) Hospital Employees' Interpersonal Relationship towards Momentary and Non-momentary Incentives in Public Enterprises. The State of Healthcare in Nigeria. Onitsha West and Solomon Publishing Co. Ltd. 438 - 471.

[26] Jordan, P. J., Ashkanasy, N. M., Härtel, C. E. J., \& Hooper, G. S. (2002). Workgroup Emotional Intelligence: Scale Development and Relationship to Team Process Effectiveness and Goal Focus. In Human Resource Management Review, 12(2), 195-214. Retrieved April 02, 2010, from http://www.emeraldinsight.com

[27] Joshanloo, M., \& Afshari, S. (2011). Big-Five Personality Traits and Self Esteem as Predictors of Life Satisfaction in Iranian Muslim University Students. Journal of Happiness Studies, 12: 105-113.

[28] Krause, N. (2004). Lifetime Trauma, Emotional Support, and Life Satisfaction among Older Adults. The Gerontologist, 44: 615-623.

[29] Krause, N. (2006). Church-Based Social Support and Mortality. The Journals of Gerontology, 61B, S140-S146.

[30] Lyyra, T.M. \& Heikkinen, R.L. (2006). Perceived Social Support and Mortality in Older People. The Journal of Gerontology, 61 (3): S147-S152

[31] Newson, J.T., \& Schulz, R. (1996). Social Support as a Mediator between Status and Quality of Life in Older Adults. Psychology and Aging, 11: 34-44.

[32] Ogungbamila, A.B. (2011). Perceived Organisational Injustice, Negative Emotions and Emotional Intelligence as Predictors of Workplace Reactivity among Local Government Employees in South-western Nigeria. Unpublished Doctoral Thesis, University of Ibadan, Nigeria

[33] Oladipo S.E., Olapegba P.O. \& Adenaike F. A. (2010). Evidence of Low Life Satisfaction among Undergraduates in Southwest Nigeria. International Journal of Asian Social Science 2(10):1718-1723

[34] Onyishi, I.K., Okongwu, O.E., Ugwu, F.O. (2012). Personality and Social Support as Predictors of Life Satisfaction of Nigerian Prisons. European Scientific Journal September edition vol. 8, No.20 ISSN: 1857 - 7881

[35] Qquoidbach, J. \& Hansenne, M. (2000). The Impact of Trait Emotional Intelligence on Nursing Team Performance and Cohesiveness. In Journal of Professional Nursing, 25(1), 23-29. Retrieved March 02, 2010, from http:// www. emeraldinsight.com

[36] Robins, R.W., \& Trzesniewski, K.H. (2005). Self-Esteem Development Across the Lifespan. Current Directions in Psychological Science, 14(3), 158-162.

[37] Rode, J. C. (2004). Job Satisfaction and Life Satisfaction Revisited: A Longitudinal Test of an Integrated Model. Human Relation, 57: 1205-1230.

[38] Salovey, P., Mayer, J.D., Goleman, S.L., Turvey, C., \& Palfai, T.P. (1995). Emotional Attention, Clarity, and Repair: Exploring Emotional Intelligence using the Trait Meta-Mood Scale. In J.W. Pennebaker (Ed.), Emotion, disclosure and health (pp. 12-154). Washington, DC: American Psychological Association

[39] Schimmack, U., Oishi, S., Furr, R. M. \& Funder, D. C. (2004). Personality and Life Satisfaction: A Facet-Level Analysis. Personality and Social Psychology Bulletin, 30: 1062-1075.

[40] Seeman, T.E. (2000). Health Promoting Effects of Friends and Family on Health Outcomes in Older Adults. American Journal of Health promotion, 14(6), 362-370

[41] Seitz, D. C. M., Hagmann, D., Besier, T., Dieluweit, U., Debatin, K., Grabow, D., Kaatsch, P., Henrich, G., \& Goldbeck, L. (2011). Life Satisfaction in Adult Survivors of Cancer during Adolescence: What Contributes to the Later Satisfaction with Life. Quality of Life Research, 20: 225-236. 
[42] Seligman, M. E. P. (2002) Authentic Happiness: Using the New Positive Psychology to Realize your Potential for Lasting Fulfillment. New York: Free Press.

[43] Seligman, M. E. \& Csiksentunihalyi, M. (2002) Positive Psychology: An introduction. American Psychologist, 55:5-14.

[44] Stough, C., Saklofske, D. H., \& Parker, J. D. (2009) Assessing Emotional Intelligence: Theory, Research, and Applications. Retrieved April 02, 2010 from http://www.sciencedirect.com

[45] Strine, T.W., Chapman, D.P., Balluz, L., \& Mokdad, A.H. (2008). Health- Related Quality of Life and Health Behaviors by Social and Emotional Support: Their relevance to psychiatry and medicine. Social Psychiatry and Epidemiology, 43, 151159

[46] Sun, H.M., Zhang, J.J., Fu, X.D. (2007). Psychological Status, Coping and Social Support of People Living with HIV/AIDS in Central China, Journal of Public Health Nursing; 24:132 - 140

[47] Sy, T., Tram, S., \& O’Hara, L. A. (2006). Relation of Employee and Manager Emotional Intelligence to Job Satisfaction and Performance. In Journal of Vocational Behavior, 68, 461-473. Retrieved April 02, 2010, from http:// www.em eraldinsight.com

[48] Thorndike, E.L. (1920). Intelligence and its uses. Harper's Magazine, 140, 227-235.

[49] Uchino, B.N. (2006). Social support and health: A review of physiological processes potentially underlying links to disease outcomes. Journal of Behavioral Medicine, 29(4), 377-387.

[50] Umeh, C. S. (2004). The Impact of personality characteristics on student's adjustment on campus. Unpublished Ph.D thesis Department of Psychology, University of Lagos.

[51] Veenhoven, R. (1984) Conditions of happiness. Dordrecht: Reidel, (reprinted 1991 by Kluwer Academic.)

[52] Veenhoven, R. (1989) How Harmful is Happiness? Consequences of enjoying life or not. University Press Rotterdam.

[53] Veenhoven, R. (1990) Inequality in Happiness. Inequality in Countries Compared between Countries. Madrid: Paper Presented at the 12th ISA Conference.

[54] Veenhoven, R. (1991). Is Happiness Relative? Social Indicators Research, 24, 1-34.

[55] Veenhoven, R. (1993). Happiness in Nations. Subjective Appreciation of Life in 56 Nations(1946-1992). RISBO, Studies in Social and Cultural Transformation 2. Erasmus University Rotterdam, Netherlands. (www2.eur.nl/fsw/ happiness/hap_ nat/nat_fp.htm) Ruut Veenhoven 36 The study of life satisfaction

[56] Veenhoven, R. (1994). Correlates of Happiness. RISBO, Studies in Social and Cultural Transformation 3. Erasmus University Rotterdam, Netherlands. (www2.eur.n1/fsw/research/happiness/hap_cor/cor_fp.htm).

[57] Veenhoven, R. (1995). The Cross-National Pattern of Happiness. Social Indicators Research, 34, 33-68.

[58] Vitterso, J. (2001). Personality Traits and Subjective Well-being: Emotional Stability, not Extraversion, is Probably the Important Predictor. Personality and Individual Differences, 31: 903-914.

[59] Williams, P., Barclay, L., \& Schmied, V. (2004).Defining social support in context: A necessary step in improving research, intervention, and practice. Qualitative Health Research, 12, 942-959.

[60] Williams, P., Barclay, L., \& Schmied, V. (2004).Defining social support in context: A necessary step in improving research, intervention, and practice. Qualitative Health Research, 12, 942-959.

[61] Wong, S. S., Oei, T. P. S., Ang, R. P., Lee, B. O., Ng, A. K., \& Leng, V. (2007). Personality, Meta-Mood Experience, Life Satisfaction, and Anxiety in Australian versus Singaporean Students. Current Psychology, 26: 109-120.

[62] Wright, T. A., \& Cropanazano, R. (2000). Psychological Well-Being and Job Satisfaction as Predictor of Job Performance. Journal of Occupational Health Psychology, 5: 84-94.

[63] Zhou, J., George, J. M. (2003). Awakening Employee Creativity: The Role of Leader Emotional Intelligence. Leadership Quarterly, 14, $545-568$.

[64] Zimet, G.D., Powell, S.S., Farley, G.K., Werkman, S. \& Berkoff, K.A. (1990). Psychometric characteristics of the Multidimensional Scale of Perceived Social Support. Journal of Personality Assessment, 55, 610-17.

[65] Zimet, G.D., Dahlem, N.W., Zimet, S.G. \& Farley, G.K. (1988). The Multidimensional Scale of Perceived Social Support. Journal of Personality Assessment, 52, 30-41 